\title{
Efficient hydrogen storage in up-scale metal hydride tanks as possible metal hydride compression agents equipped with Aluminium extended surfaces
}

\author{
Evangelos I. Gkanas ${ }^{1,2^{*}}$, David M. Grant ${ }^{1}$, Martin Khzouz ${ }^{1,2}$ Alastair D. Stuart ${ }^{1}$, Kandavel Manickam ${ }^{1}$, \\ Gavin S. Walker ${ }^{1}$ \\ ${ }^{1}$ Division of Materials, Mechanics and Structures Research Division, Faculty of Engineering, University of \\ Nottingham, Nottingham, NG7 2RD, UK \\ ${ }^{2}$ School of Mechanical, Aerospace and Automotive Engineering, Faculty of Engineering, Environment and \\ Computing, Gulson Road, Coventry CV1 2JH, United Kingdom \\ *Email: ac1029@coventry.ac.uk
}

\begin{abstract}
In the current work, a three-dimensional computational study regarding coupled heat and mass transfer during both the hydrogenation and dehydrogenation process in upscale cylindrical metal hydride reactors is presented, analysed and optimized. Three different heat management scenarios were examined at the degree to which they provide improved system performance. The three scenarios were: 1) Plain embedded cooling/heating tubes, 2) transverse finned tubes and 3) longitudinal finned tubes. A detailed optimization study was presented leading to the selection of the optimized geometries. In addition, two different types of hydrides, LaNi5 and an AB2-type intermetallic were studied as possible candidate materials for using as the first stage alloys in a two-stage metal hydride hydrogen compression system. As extracted from the above results, it is clear that the case of using a vessel equipped with 16 longitudinal finned tubes is the most efficient way to enhance the hydrogenation kinetics when using both LaNi5 and the AB2-alloy as the hydride agents. When using LaNi5 as the operating hydride the case of the vessel equipped with 60 embedded cooling tubes presents the same kinetic behaviour with the case of the vessel equipped with 12 longitudinal finned tubes, so in that way, by using extended surfaces to enhance the heat exchange can reduce the total number of tubes from 60 to 12 . For the case of using the AB2-type material as the operating hydride the performance of the extended surfaces is more dominant and more effective comparing to the case of using the embedded tubes, especially for the case of the longitudinal extended surfaces.
\end{abstract}

Keywords: Heat Management; Metal Hydride Compression Systems; $A B_{2}$-type intermetallics; Extended Surfaces

\section{Introduction}

Hydrogen is a promising alternative energy carrier that could potentially facilitate the transition from fossil fuels to sources of green energy due to its high energy density (141 $\mathrm{MJ} / \mathrm{kg}$ ), variety of potential sources and low environmental impact [1]. Hydrogen can be stored as a high pressure gas or low temperature liquid or alternately, it can, by undergoing a 
chemical reaction, be stored in solid form metal hydrides or cryo-adsorbents [2, 3]. Issues associated with hydrogen storage materials are the storage capacity, the thermal stability of the hydride, the kinetics of hydrogenation and dehydrogenation, thermophysical properties and crystal structures. Specifically fast reaction kinetics and high hydrogen storage capacity are the most important properties of the alloys used in thermal devices [4], compression systems [5-7] and heat pumps [8, 9]. Generally the limiting factor controlling the hydrogen charging/discharging in a metal hydride reactor is the rate at which heat can be transferred between the hydride and the reactor. Due to the exothermic nature of the hydrogenation process, large amounts of heat are produced inside the reactor, forcing the equilibrium pressure to increase and subsequently lowering the driving force for the hydrogen storage. On the other hand, providing heat and consequently lowering the internal pressure is necessary for the dehydrogenation process to take place. The thermal management of a metal hydride reactor must take into account both the cooling during the hydrogenation process heating during the dehydrogenation process. Two active heat management techniques can be employed to accomplish this, internal heat management and external heat transfer $[10,11]$. Heat exchangers are used in many industrial applications the most widely used being those intended to exchange heat between two fluids. Less attention has been given to the design of heat exchangers involving the heat flow between a stationary reacting metal hydride powder and a cooling/heating fluid as required in the field of solid state hydrogen storage.

Though many efforts are dedicated to enhancing the rate of the external heat transfer, the performance of the metal hydride systems cannot reach until now the practical expectations [12]. Therefore, internal heat transfer enhancements have become more attractive and can roughly divided in two ways: 1) Enhancement of the thermal conductivity of the metal hydride powder by insertion of aluminium foam [13-15], copper wire net structure [16] or by creating metal hydride compacts [17-20], 2) Integration of heat exchangers inside the bed such as embedded heat exchanger tubes [21-23], finned tube heat exchangers [24-27], spiral heat exchangers [28, 29] or heat pipes [30].

In a previous work [31], the authors described the simulation study of the operation of a two-stage metal hydride hydrogen compression system and studied the combination of different materials. Heat management of the reactors did not go any further than identifying that both reactors had external jackets for the heating/cooling of the hydrides, as the main focus of the study was the understanding the operation of the coupled compressor stages. In the current work, three different heat management scenarios are studied numerically using Finite Element Analysis software COMSOL Multiphysics 4.4. in order to decide which scenario, if incorporated into an up-scale metal hydride tank, will result in the most efficient operation of the compression system. The first scenario involves the use of a differing number of plain cooling/heating tubes embedded in the reactor. The second scenario includes transverse $\mathrm{Al}$ surfaces extending from the cooling/heating tubes and the third scenario deals with longitudinal Al extended surfaces. For each scenario, a two dimensional study was conducted to optimise the number of cooling/heating tubes, diameter of the tubes (scenario 1), number of heating/cooling tubes, number of Al fins and fin thickness (scenario 2 and 3). The optimised geometry was then modelled in 3D. The results showed that the presence of the Al fins can reduce both the hydrogenation and dehydrogenation time and in terms of charging time, instead of using 60 cooling tubes only 12 or 16 finned tubes can be used with 
faster kinetics. The effect on reactor performance was also compared using two different first stage storage materials. The first material was LaNi5 and the second material was a Lavesphase AB2 Ti-Zr based intermetallic

\section{Methodology}

In the current numerical work the reactor performance was modelled by the simultaneous use of COMSOL Multiphysics chemical reactions, to implement the reaction of hydrogen with the metal hydride, and heat transfer in solids, for the heat transfer through the hydride bed and heat exchange components. Prior to conducting these simulations the performance of the model was validated using experimental results extracted from a lab-scale Sievert's type apparatus. After the validation process, the optimization study of the three scenarios was performed. For scenario 1 the impact of the number of cooling/heating tubes was explored by modelling the reactor performance using 18, 24, 30, 36, 48 and 60heat exchange tubes. For scenarios 2 and 3, three different parameters were optimised i.e., the radius, number and thickness of the fins. For all three scenarios the heating tube radius was $3.2 \mathrm{~mm}$. Table 1 presents all the details about the optimization parameters studied in the current model.

Table 1. Parameters used for the optimization study scenarios 1,2 and 3.

\subsection{Model Assumptions}

A number of assumptions were made which serve to simplify the modelling process. These were:

a) Initially the temperature and pressure profiles are uniform.

b) Thermal conductivity and specific heat of the hydrides are assumed to be constant during the compression cycle.

c) The medium is in local thermal equilibrium which implies that there is no heat transfer between solid and gas phases

d) Hydrogen is treated as an ideal gas from a thermodynamic point of view.

e) The bed void fraction remains constant and uniform throughout.

f) The characteristics, e.g., the kinetics and thermal properties, of the bed are unaffected by the number of loading and unloading cycles i.e., bed aging is neglected.

g) The bed fills the entire volume of the space between the fins and tubes. 


\subsection{Heat equation}

Assuming thermal equilibrium between the hydride powder and hydrogen gas, a single heat equation is solved instead of separate equations for solid and gas phases:

$$
\begin{aligned}
& (\rho \cdot C p)_{e} \cdot \frac{\partial T}{\partial t}+\left(\rho_{g} \cdot C p_{g}\right) \cdot \bar{v}_{g} \cdot \nabla T \\
& =\nabla \cdot\left(k_{e} \cdot \nabla T\right)+m \cdot\left(\left(\frac{\Delta \mathrm{H}}{M_{H_{2}}}\right)-T \cdot\left(C p_{g}-C p_{s}\right)\right)
\end{aligned}
$$

Where, the effective heat capacity is given by;

$$
(\rho \cdot C p)_{\mathrm{e}}=\varepsilon \cdot \rho_{g} \cdot C_{p g}+(1-\varepsilon) \cdot \rho_{s} \cdot C_{p s}
$$

and the effective thermal conductivity is given by;

$$
k_{e}=\varepsilon \cdot k_{g}+(1-\varepsilon) \cdot k_{s}
$$

The terms $\rho_{g}, C_{p g}, C_{p s}$ and $m$ refer to the density of the gas phase, the heat capacity of the gas phase, the heat capacity of the solid phase and the kinetic term for the reaction respectively.

\subsection{Hydrogen Mass Balance}

The equation that describes the diffusion of hydrogen mass inside the metal matrix is given by:

$$
\varepsilon \cdot \frac{\partial\left(\rho_{g}\right)}{\partial t}+\operatorname{div}\left(\rho_{g} \cdot \vec{v}_{g}\right)= \pm Q
$$

Where, (-) is for the hydrogenation process and $(+)$ is for the dehydrogenation process, $v_{g}$ is the velocity of gas during diffusion within the metal lattice (see chapter 2.4) and $Q$ is the so-called Mass Source term describing the mass of hydrogen diffused per unit time and unit volume in the metal lattice.

\subsection{Momentum equation}

The velocity of a gas passing through a porous medium can be expressed by Darcy's law. By neglecting the gravitational effect, the equation which gives the velocity of gas inside the metal matrix is given by:

$$
\vec{v}_{g}=-\frac{K}{\mu_{g}} \cdot \operatorname{grad}\left(\vec{P}_{g}\right)
$$

Where $\mathrm{K}$ is the permeability of the solid and $\mu_{\mathrm{g}}$ is the dynamic viscosity of gas. 


\subsection{Kinetic expression}

The reaction kinetic equation describes the expression for hydrogen mass hydrided and dehydrided per unit time and volume. The amount of hydrogen taken up is given by;

$$
m_{a}=C_{a} \cdot \exp \left[-\frac{E_{a}}{R_{g} \cdot T}\right] \cdot \ln \left[\frac{p_{g}}{P_{e q}}\right] \cdot\left(\rho_{s s}-\rho_{s}\right)
$$

The amount of hydrogen released from the hydride bed is given by;

$$
m_{d}=C_{d} \cdot \exp \left[-\frac{E_{d}}{R_{g} \cdot T}\right] \cdot\left(\frac{P_{e q}-p_{g}}{P_{e q}}\right) \cdot \rho_{s}
$$

Where $\rho_{s}$ and $\rho_{s s}$ are the density of the hydride at any time and at saturation state respectively. $C_{a b s}$ and $C_{\text {des }}$ refer to the pre-exponential constants for the hydrogenation and dehydrogenation process and the $E_{a}$ and $E_{d}$ are the activation energy for hydrogenation and dehydrogenation process respectively.

\subsection{Equilibrium Pressure.}

In order to incorporate the effect of hysteresis and the plateau slope (which is present in both stages of the compression cycle) for the calculation of the plateau pressure $\mathrm{P}_{\text {eq }}$, the following equation was used [32, 33]:

$$
\ln \frac{P_{e q}}{10^{5}}=\left\{\left[\frac{\Delta \mathrm{H}}{R T}-\frac{\Delta S}{R}\right]+\left(\varphi_{s} \pm \varphi_{0}\right) \cdot \tan \left[\pi \cdot\left(\frac{x}{x_{s a t}}-\frac{1}{2}\right) \pm \frac{S}{2}\right\}\right.
$$

The plateau slope is given by the flatness factors $\varphi_{s}$ and $\varphi_{0}$ and $\mathrm{S}$ represents the hysteresis effect which is ( $\left(\ln _{\mathrm{abs}} / \mathrm{P}_{\text {des }}\right)$ designated ' + ' for hydrogenation and '-' dehydrogenation. $x$ and $x_{\text {sat }}$ are the local hydride concentration at any given time and at saturation respectively.

\section{Validation of numerical results}

To validate the model, experiments were performed on a $0.8 \mathrm{~g}$ sample of LaNi5 powder. The sample was synthesized by arc-melting and the phase purity was validated using XRD

(Rietveld Analysis). The pressure-composition-isotherm (PCI) hydrogenation and dehydrogenation measurements were performed on a lab scale Sievert-type apparatus with a capacitance manometer (Druck PTX 620) at two different temperatures (25 and 50 oC). In addition, two different over pressures were used to demonstrate that the model could accommodate different driving pressures. The results of the modelling work compared to the experimental data show good agreement with a maximum deviation of less than $5 \%$ as illustrated in Fig. 1. 
Fig.1. Validation of the predicted amount of hydrogen stored (3a) for different temperatures and different pressures and released (3b) for two different temperatures with experimental data extracted from a lab scale Sievert type apparatus. The experimental results (red dots) with the simulation results (black lines) are in good agreement with a maximum deviation less than $5 \%$.

\section{Tank design geometries}

The metal hydride reactors considered in the current study were cylindrical , 316 stainless steel with a wall thickness of $3 \mathrm{~mm}$. The total length of the reactor was $400 \mathrm{~mm}$ and the internal radius was $52.55 \mathrm{~mm}$, resulting in an internal volume of $3.4410^{-3} \mathrm{~m}^{3}$. For the first scenario the arrangements of the 18/24/30/36/48/60 embedded cooling/heating heat exchangers, similar to those used by Anbarasu et al [10], are presented in Fig 2.

Fig 2. The geometries used for the study of scenario 1. Different arrangements of the co-central tubes were used and the different number of tubes used was 18-24-30-36-48 and 60. The central tube used for the hydrogen delivery during the hydrogenation process and for the hydrogen expulsion during the dehydrogenation process.

Fig. 3 illustrates scenarios 2 and 3 where the heat exchange tubes are equipped with $\mathrm{Al}$ extended surfaces. A single tube is shown in Figures 3(a) and Fig 3(c) equipped with transverse and longitudinal Al fins respectively. The tubes are shown assembled in the reactor for 8 transverse finned tube, fig (b) and 16 longitudinal Al fins, Fig 3(d). In both geometries, the central tube enables the delivery of hydrogen along the axis of the bed.

Fig 3. The geometries used for the study of scenario 2 and scenario 3. Figure $3 a$ and $3 c$ shows a single heating/cooling equipped with transverse and longitudinal fins respectively. Figure $3 b$ shows the case of using 8 transverse finned tubes within the reactor and Figure 3d the case of using 12 longitudinal finned tubes.

\section{Optimization Objectives and Control Factors}

The charging/discharging time is of major importance for the effective performance of a metal hydride tank. The purpose of the present optimization process is to obtain the parameters of the systems that lead to the minimum charging/discharging time $\left(t_{s}\right)$. The charging/discharging time $\left(t_{s}\right)$ is the time that is required for the average reacted fraction to rise from 0.1 to 0.9 for the hydrogenation process and to decrease from 0.9 to 0.1 for the dehydrogenation process. The optimization process was performed for the cases of the transverse and the longitudinal finned geometries and the optimized geometries will be compared to each other as well as with the embedded tube geometries. Table 2 presents the control factors and the values for the case of the transverse finned geometry and Table 3 presents the control factors and the values for the case of the longitudinal finned geometry.

Table 2. Control factors for the transverse finned geometry and their values

Table 3. Control factors for the longitudinal finned geometry and their values 
According to the optimization analysis, the optimum geometry for the transverse finned geometry is the combination of 30 fins with radius $8 \mathrm{~mm}$ and thickness $2 \mathrm{~mm}$, while for the case of longitudinal fins the optimum geometry is the case with 12 fins with fin height $5 \mathrm{~mm}$ and thickness $0.5 \mathrm{~mm}$. Fig. 4 shows the temperature distribution for both the transverse and the longitudinal case during the optimization process in two dimensions.

Fig. 4. Temperature distribution for both the case of using the transverse and longitudinal fins during the optimization process.

\section{Results and Discussion}

5.1 Hydrogenation Process

\subsubsection{Scenario 1 - Embedded Cooling Tubes}

The initial temperature and the temperature of the cooling fluid during the hydrogenation process for all the studied cases was $20{ }^{\circ} \mathrm{C}$ and the supply pressure was selected at 15 bar, which is the pressure that a commercial electrolyser can provide. The maximum time considered for the hydrogenation process was $2000 \mathrm{~s}$, due to the very strict requirements that a compression system demands. For scenario 1, it was observed that the average temperature of the hydride bed reaches the temperature of the cooling fluid faster for the cases where the reactor includes higher number of tubes; see Fig 5(a). Due to the exothermic nature of the hydrogenation process the average bed temperature will initially increase. As the relatively large amount of heat is transferred away from the bed the average temperature will start to decrease towards that of the cooling fluid. The presence of 48 and 60 tubes provides the largest increase in primary heat transfer area which in turns provides the most effective heat management, Fig 5(a). For comparison, Fig. 5b shows the average bed temperature when using the combination of the heat exchangers and external jacket. In that case, the cooling rate is faster comparing with the case of using only the cooling tubes and the system is able to reach the temperature of the cooling fluid faster. This temperature behaviour can impact the hydrogenation kinetics as presented in Fig. 5c and Fig. 5d. With the increase of the number of the cooling tubes in the system the hydrogenation process is faster comparing to the cases with lower number of tubes. Fig. 5e also presents a comparison of the case including only the cooling tubes and the combination of both cooling tubes and external jacket for the different number of tubes with the time needed for the system to reach $\mathrm{X}=0.9$ as indicated in chapter 5 . As mentioned earlier, the maximum hydrogenation time considered was $2000 \mathrm{~s}$, so this is the upper time in Fig. 5e. According to Fig. 5e, it would appear that the case of 18 and 24 tubes will fail to achieve the target hydrogen charging time of $2000 \mathrm{~s}$ where as for the case of 30 tubes either combination of tubes and tubes plus external jacket could reach $\mathrm{X}=0.9$ in less than 2000 s. For the case of 36 tubes, both cases can reach $X=0.9$ in less than $2000 \mathrm{~s}$, but the combination case (1726 s) is faster than the case of only cooling tubes (1970 s) at almost 4 min. When 48 tubes are inserted in such geometry for both cases the kinetics of the hydrogenation process are faster and the combination case is faster by more than 4 min. Finally, for the case of 60 tubes the combination of the cooling tubes with the external jacket has faster response for the hydrogenation process compared to the cooling tubes by almost 4 min. According to these results, it seems that the presence of 48 and 60 tubes in the metal hydride container can enhance the hydrogenation kinetics at least by $10 \mathrm{~min}$, while the 
comparison between the usage of an extra external jacket seem to accelerate the reaction by almost 4 min for all the cases.

Fig 5. Figure $5 a$ and $5 b$ shows the average temperature of the hydride bed during the hydrogenation process. Figure $5 c$ and $5 d$ present the average hydrogenation fraction during the hydrogenation process. Figure $5 b$ and $5 d$ also present the effect of the additional heat management when using an external jacket in combination with the embedded tubes. Figure 5e shows the time needed for the bed to reach the average hydrogenation fraction $X=0.9$ and compare the response time for the case of using only the tubes and the case of combine the tubes with the external jacket.

\subsubsection{Scenario 2 - Transverse Finned Tubes}

According to the optimization study presented in chapter 5, for the case of transverse fins, the optimization analysis, after simulating 125 different cases, the optimum geometry of the finned tubes is the combination of 30 fins (distance between the fins $9.8 \mathrm{~mm}$ ) with radius 8 $\mathrm{mm}$ and thickness $2 \mathrm{~mm}$. Three different cases were examined, $8-12$ and 16 finned tubes, inserted inside the metal hydride container. The dimension and the total mass of the material inside the tank is the same as the previous scenario, in order to be able to compare the results for the current scenario with the previous one. Fig. 6a presents the kinetics of the hydrogenation behaviour of the material for the case of $8-12$ and 16 finned tubes when using only the finned tubes as the heat exchangers. Similar to the previous results, increasing of the number of the tubes can enhance the kinetics of the hydrogenation capacity due to the faster removal of the exothermically produced heat. Fig 6.b presents the kinetics of the hydrogenation behaviour of the material for the case of $8-12$ and 16 finned tubes when using the combination of the finned tubes and an external jacket. According to the results, the combination of both jacket and tubes serve to increase the rate of the hydrogenation reaction. Fig. 6c shows the comparison of the time for the material to reach $X=0.9$ during the hydrogenation process for 8, 12 and 16 finned tubes for both the case of using only the finned tubes and the combination of the finned tubes and the external jacket. In both cases the 8 finned tube arrangement is unable to reach the target of $X=0.9$ in less than $2000 \mathrm{~s}$. When using 12 finned tubes, it is only the combination of jacket and tubes that provide sufficient heat management that the system is able to reach $X=0.9$ in under $2000 \mathrm{~s}$. In fact $\mathrm{X}=0.9$ is reached in $1692 \mathrm{~s}$, more than 5 min faster than that achieved by the finned tubes alone. Finally, when 16 finned tubes are installed in the container, in both cases the system is able to achieve $\mathrm{X}=0.9$ in less than $2000 \mathrm{~s}$, and the case of the combined heat management is almost 4 min faster.

Fig. 6. The kinetics during the hydrogenation process for the case of using 8-12-16 transverse finned tubes. Figure $6 b$ present the case of using an additional external jacket in combination with the finned tubes. Figure $6 c$ shows the time needed for the hydride to reach the hydrogenation fraction $X=0.9$ for both the cases of using and non-using the external jacket combined with the finned tubes.

\subsubsection{Scenario 3 - Longitudinal Finned Tubes}

The current scenario involves the study of the usage of Al fins located longitudinal on the cooling tubes as presented in Fig. 3c and 3d. According to the optimization study presented in chapter 5, for the case of longitudinal fins, the optimization analysis, after simulating 125 
different cases, the optimum geometry of the finned tubes is the case including 12 fins with fin height $5 \mathrm{~mm}$ and thickness $0.5 \mathrm{~mm}$ as presented in Fig. 3c and 3d. Three different cases were examined in terms of the number of the finned tubes inserted inside the metal hydride container, 8 - 12 and 16 finned tubes. The dimension and the total mass of the material inside the tank is the same as the previous scenario, in order to be able to compare the results for the current scenario with the previous scenarios discussed. The material inside the reactor has the properties of $\mathrm{LaNi}_{5}$ as in the previous case. Fig. 7a presents the kinetics of the hydrogenation behaviour of the material for the case of $8-12$ and 16 finned tubes when using only the finned tubes as the heat exchangers. Similar to the results presented at chapter 6.1.2 the increasing of the number of the tubes can enhance the kinetics of the hydrogenation capacity due to the faster removal of the produced heat during the hydrogenation process. Fig 7.b presents the kinetics of the hydrogenation behaviour of the material for the case of $8-12$ and 16 finned tubes when using the combination of the finned tubes and an external jacket. According to the results, the combination of both heat treatment ways increases the hydrogenation reaction. Fig. 7c shows the comparison of the time for the material to reach $\mathrm{X}=0.9$ during the hydrogenation process for 8,12 and 16 finned tubes for both the case of using only the finned tubes and the combination of the finned tubes and the external jacket. When using 8 finned tubes, the system is not able to reach the target of $\mathrm{X}=0.9$ in less than $2000 \mathrm{~s}$ in both cases. When using 12 finned tubes, the case of the combined heat management is faster by slightly less than 4 min compared to the case of using only the finned tubes. For the case of using 16 finned tubes, the difference between the two heat management cases is small (around $36 \mathrm{~s}$ ). According to these results, for the case of 16 finned tubes it seems that the presence of the external jacket does not affect the hydrogenation behaviour of the system and the presence of the finned tubes has a dominant effect at the performance of the system. Furthermore, the kinetic behaviour between the case of using 12 and 16 finned tubes has a small difference as well, indicating that increasing the number of the tubes for the longitudinal finned case over 12 finned tubes does not affect much the kinetics of the hydrogenation process.

Fig. 7. The kinetics during the hydrogenation process for the case of using 8-12-16 longitudinal finned tubes. Figure $7 b$ present the case of using an additional external jacket in combination with the finned tubes. Figure $7 c$ shows the time needed for the hydride to reach the hydrogenation fraction $X=0.9$ for both the cases of using and non-using the external jacket combined with the finned tubes.

\subsection{Dehydrogenation Process}

\subsubsection{Scenario 1 - Embedded Cooling Tubes}

According a previous work of the authors [36] the operation temperatures of the studied compression system were $20^{\circ} \mathrm{C}$ (hydrogenation process) and $130^{\circ} \mathrm{C}$ (dehydrogenation process), so in order to study the current system, the dehydrogenation process the initial temperature and the temperature of the heat exchange fluid is $130^{\circ} \mathrm{C}$. Fig. 8 a shows the average temperature evolution within the metal hydride tank while the heat exchange system is the heating embedded tubes. The average hydride bed temperature initially reduces to its lowest value due to the rapid endothermic reaction that occurs during the dehydrogenation process and due to the low thermal conductivity of the hydride powder, the hydride use the 
heat from itself to maintain the reaction while slowly the temperature increasing slowly towards the temperature of the heating fluid. As extracted from the results, the reactor with 48 and 60 tubes can recover the heat from the heating tubes faster than the other configurations. This is due to the heat transfer area aids higher heat transfer rates from the heating tubes. The effect of adding an external jacket is presented in Fig. 8b. As discussed in chapter 6.1.1 the temperature recover in that case is faster comparing to the case only when the heat exchange is performed by the heating tubes. Fig. 8c and 8d shows the profile of the dehydrogenation capacity comparing the two different heat treatment cases. According to the results from Fig. 8e, it seems that for the case of 18 and 24 tubes the hydrogen discharging time was $2000 \mathrm{~s}$ and/or more and for the case of 30 tubes only the case of the combination of heating fluid and the external jacket could reach $X=0.1$ in less than $2000 \mathrm{~s}$ and more specifically in $1296 \mathrm{~s}$. For the case of 36 tubes, both cases can reach $X=0.1$ in less than 2000 $\mathrm{s}$, but the combination case (905 s) is faster than the case of only cooling tubes (1400 s) at almost $8 \mathrm{~min}$. When 48 tubes are inserted in such geometry for both cases the kinetics of the hydrogenation process are faster and the combination case is faster by almost $8 \mathrm{~min}$. Finally, for the case of 60 tubes the combination of the heating tubes with the external jacket has faster response for the hydrogenation process compared to the cooling tubes by almost $7 \mathrm{~min}$. According to these results, it seems that the presence of 48 and 60 tubes in the metal hydride container can enhance the dehydrogenation kinetics at least by $10 \mathrm{~min}$, while the comparison between the usage of an extra external jacket seem to accelerate the reaction by almost 7-8 min for all the cases. It has to be noted that by comparing the results extracted from the hydrogenation process and the dehydrogenation process, the external jacket has more impact at the dehydrogenation process rather than the hydrogenation.

Fig 8. Figure $8 a$ and $8 b$ shows the average temperature of the hydride bed during the dehydrogenation process. Figure $8 c$ and $8 d$ present the average dehydrogenation fraction during the dehydrogenation process. Figure $8 b$ and $8 d$ also present the effect of the additional heat management when using an external jacket in combination with the embedded tubes. Figure $8 e$ shows the time needed for the bed to reach the average dehydrogenation fraction $X=0.1$ and compare the response time for the case of using only the tubes and the case of combine the tubes with the external jacket.

\subsubsection{Scenario 2 - Transverse Finned Tubes}

For the current study the geometry used is exactly the same with the geometry described to chapter 6.1.2. Three different cases were examined in terms of the number of the finned tubes inserted inside the metal hydride container, $8-12$ and 16 finned tubes. Fig. 9a present the kinetics of the dehydrogenation behaviour of the material for the case of $8-12$ and 16 finned tubes when using only the finned tubes as the heat exchangers. Similar to the previous results, increasing of the number of the tubes can enhance the kinetics of the dehydrogenation capacity due to the faster heat supply from the heating tubes which results to the higher heat exchange area between the tubes and the hydride. Fig. 9b present the kinetics of the dehydrogenation behaviour of the material for the case of $8-12$ and 16 finned tubes when using the combination of the finned tubes and an external jacket. According to the results, the combination of both heat treatment ways increases the kinetics of the hydrogenation reaction. Fig. 9c shows the comparison of the time for the material to reach $X=0.1$ during the dehydrogenation process for 8, 12 and 16 finned tubes for both the case of using only the 
finned tubes and the combination of the finned tubes and the external jacket. When using 8 finned tubes, the system is not able to reach the target of $X=0.1$ in less than $2000 \mathrm{~s}$ in both cases. When using 12 finned tubes, for the case of using only the tubes the system is not able to reach the target capacity at $2000 \mathrm{~s}$, while for the combination heat management case the system is able to reach $\mathrm{X}=0.1$ in $1313 \mathrm{~s}$, more than $11 \mathrm{~min}$ faster compared to the heat treatment by only the finned tubes. Finally, when 16 finned tubes are installed in the metal hydride tank, in both cases the system is able to achieve $X=0.1$ in less than $2000 \mathrm{~s}$. The case of the combination of both finned tubes and external heating is more than 6 min faster comparing to the case of using only the finned tubes within the tank.

Fig 9. The kinetics during the dehydrogenation process for the case of using 8-12-16 transverse finned tubes. Figure $9 b$ present the case of using an additional external jacket in combination with the finned tubes. Figure $9 c$ shows the time needed for the hydride to reach the hydrogenation fraction $X=0.1$ for both the cases of using and non-using the external jacket combined with the finned tubes

\subsubsection{Scenario 3 - Longitudinal Finned Tubes}

The current scenario involves the study of the usage of Al fins located longitudinal on the cooling tubes as presented in Fig. $3 \mathrm{c}$ and $3 \mathrm{~d}$. Three different cases were examined in terms of the number of the finned tubes inserted inside the metal hydride container, $8-12$ and 16 finned tubes. Fig. 10a shows the kinetics of the dehydrogenation behaviour of the material for the case of $8-12$ and 16 finned tubes when using only the finned tubes as the heat exchangers while Fig. 10b present the kinetics of the dehydrogenation behaviour of the material for the case of $8-12$ and 16 finned tubes when using the combination of the finned tubes and an external jacket. According to the results, the combination of both heat treatment ways increases the kinetics of the hydrogenation reaction. Fig. 10c shows the comparison of the time for the material to reach $\mathrm{X}=0.1$ during the dehydrogenation process for 8,12 and 16 finned tubes for both the case of using only the finned tubes and the combination of the finned tubes and the external jacket. When using 8 finned tubes, the system is not able to reach the target of $\mathrm{X}=0.1$ in less than $2000 \mathrm{~s}$ in both cases as indicated to the previous scenarios. When using 12 finned tubes, in both cases the dehydrogenation process becomes faster and both cases are able to achieve $X=0.1$ in less than 2000 s. The single tube case can deliver the dehydrogenation process at $1147 \mathrm{~s}$, while the combination of tubes and the external jacket is faster by less than 5 min and can deliver $\mathrm{X}=0.1$ in 849 s. Finally, when 16 finned tubes are installed in the metal hydride tank, in both cases the system is able to achieve $\mathrm{X}=0.1$ in less than $2000 \mathrm{~s}$. The case of the combination of both finned tubes and external heating is less than 3 min faster comparing to the case of using only the finned tubes within the tank.

Fig 10. The kinetics during the hydrogenation process for the case of using 8-12-16 longitudinal finned tubes. Figure $10 \mathrm{~b}$ present the case of using an additional external jacket in combination with the finned tubes. Figure 10 c shows the time needed for the hydride to reach the hydrogenation fraction $X=0.1$ for both the cases of using and non-using the external jacket combined with the finned tubes. 
5.2 Comparison of the $\mathrm{LaNi}_{5}$ and $\mathrm{AB}_{2}$-type materials performance during the hydrogenation process

The performance of a metal hydride hydrogen compression system depends on the characteristics of the operating hydride materials. The most important characteristics are the charging/discharging times (kinetics), the maximum reversible amount of hydrogen that the material can store/release and the operating temperatures. $\mathrm{LaNi}_{5}$ is a well-studied material with relatively fast kinetics, a reversible capacity of $1.45 \mathrm{wt} \%$, low operating temperatures and with a flat plateau and small hysteresis. In comparison the Laves phase $\mathrm{AB}_{2}$-type intermetallics also operates at low temperatures, can achieve higher dehydrogenation pressures but has a sloping plateau with higher hysteresis effects. Usually the maximum hydrogenation capacity of such materials is in the range of 1.2 to $2.5 \mathrm{wt}$. \%. Both materials are possible candidates for the first stage of a two-stage compression system as discussed in [36]. The first material is $\mathrm{LaNi}_{5}$ and the second material is a Ti-Zr-Mn based $\mathrm{AB}_{2}$-type intermetallic synthesized, characterized and tested at the University of Nottingham. The materials performance was compared for all the geometries described for scenario's 1, 2 and 3. Fig. 11(a) presents the hydrogenation kinetics for the LaNi5 and the $A_{2}$-type for the case of the container including cooling tubes. According to the results from chapter 6.1.1, the case of 48 and 60 embedded tubes presents the fastest kinetics and for clarity, Fig. 11a deals only with these two cases. As extracted from Fig. 11a, the $\mathrm{AB}_{2}$-type presents faster kinetics at the beginning of the hydrogenation process compared to $\mathrm{LaNi}_{5}$, but afterwards $\mathrm{LaNi}_{5}$ reaches $\mathrm{X}=0.9$ faster by less than $1 \mathrm{~min}$ for the cases of using 36 and 60 tubes and $71 \mathrm{~s}$ for the case of using 48 tubes as shown in Fig. 11b. For that case it seems that the kinetic performance of both materials is almost the same. Fig. 11c and 11d shows the comparison for the two materials for the case of using the transverse finned tubes. For the case of using 8 and 12 finned tubes both materials are unable to achieve $X=0.9$ in less than $2000 \mathrm{~s}$ and for the case of using 16 finned tubes, both materials can achieve $X=0.9$ in less than $2000 \mathrm{~s}$ and the $\mathrm{AB}_{2}-$ type can is faster than $\mathrm{LaNi}_{5}$ by $65 \mathrm{~s}$. Fig. 11e and $11 \mathrm{f}$ shows the comparison for the two materials for the case of using the longitudinal finned tubes. For the case of using 8 finned tubes both materials are unable to achieve $X=0.9$ in less than $2000 \mathrm{~s}$ and for the case of using 12 and 16 finned tubes, both materials can achieve $X=0.9$ in less than $2000 \mathrm{~s}$ and more specific for the case of using 12 finned tubes $\mathrm{LaNi}_{5}$ can achieve $\mathrm{X}=0.9$ in 1600 s while the $\mathrm{AB}_{2}$-type can achieve $\mathrm{X}=0.9$ faster by more than $4 \mathrm{~min}$ and for the case of using 16 finned tubes $\mathrm{LaNi}_{5}$ can achieve $\mathrm{X}=0.9$ in 1270 s while the $\mathrm{AB}_{2}$-type can achieve $\mathrm{X}=0.9$ faster by more than $5 \mathrm{~min}$. A very interesting outcome of the current analysis is the fact that for the embedded tube and the transverse finned tube geometry, there is not much difference in the time both materials can achieve $\mathrm{X}=0.9$ (the maximum difference is about $1 \mathrm{~min}$ for both materials), while for the case of the longitudinal finned geometry, the $\mathrm{AB}_{2}$-type material seems to present a much faster response comparing to $\mathrm{LaNi}_{5}$.

Fig 11. Comparison of the two candidate materials proposed as agents for using as the first stage of a compression system LaNis and AB2-type intermetallic. Figure $11 a$ and $11 b$ present the comparison of the performance of the two materials when using the embedded tubes as the heat management agents. Figure $11 \mathrm{c}$ and 11d shows the performance and comparison of the two materials for the case of using transverse finned tubes, while Figure 11e and 11f shows the comparison when using longitudinal finned tubes. 


\subsection{Comparison of scenarios 1, 2 and 3.}

For the three different heat management scenarios the most effective heat management measures were: 48 embedded heat exchanger tubes, 60 embedded heat exchanger tubes, 12 transverse finned tubes, 16 transverse finned tubes, 12 longitudinal finned tubes and 16 longitudinal finned tubes. Fig. 12a shows the comparison of all six cases, when using $\mathrm{LaNi}_{5}$ as the operating material. It has to be noted that all the initial conditions of temperature and pressure are the same for the comparison study. For clarity, Fig. 12b shows the same comparison but focused on the last $1000 \mathrm{~s}$ of the hydrogenation reaction. According to the results, when using $\mathrm{LaNi}_{5}$ as the hydride material the fastest kinetics are observed in the case of using 16 longitudinal finned tubes as the heat exchangers, followed by the case of using 16 transvers finned tubes (almost 3 min slower), 12 longitudinal finned tubes (almost 4.5 min slower) and 60 embedded cooling tubes (almost 4.5 min slower). The cases of using 48 embedded cooling tubes and 12 transverse finned tubes are slower and the using of 12 transverse finned tubes is not able to reach $X=0.9$ in less than $2000 \mathrm{~s}$. It has to be noted that during the first $1000 \mathrm{~s}$ of the hydrogenation reaction most of the heat treatment cases present almost the same kinetic behaviour and especially the cases of using 60 embedded tubes, 16 transverse finned tubes and 16 longitudinal finned tubes. Fig. 12c shows the comparison of the heat management cases when using the $\mathrm{AB}_{2}$-type material described earlier as the operating hydride. In that case, all the conditions were exactly the same with the conditions used for the case of using $\mathrm{LaNi}_{5}$ as the operating material. For the first $1000 \mathrm{~s}$, according to Fig. 12c it is extracted that unlike the case of using $\mathrm{LaNi}_{5}$, for the $\mathrm{AB}_{2}$-type, the heat management cases present different kinetic behaviour, where the 16 longitudinal finned tubes and the 60 embedded tubes present fast kinetic at the beginning of the hydrogenation reaction, while all the rest cases present slower response. For the final $1000 \mathrm{~s}$ of the hydrogenation reaction, as illustrated in Fig. 12d, the vessel with the 16 longitudinal finned tubes can reach $x=0.9$ in less than $1000 \mathrm{~s}$ (937 s), followed by the case of the vessel with 12 longitudinal finned tubes (slower by $7.5 \mathrm{~min}$ ) and the vessel with 16 transverse finned tubes (slower by more than $8 \mathrm{~min}$ ). The vessel equipped with 60 embedded cooling tubes instead the fast kinetics at the beginning of the reaction, reaches a smoother reaction rate at the final stage of the reaction and is able to reach $\mathrm{X}=0.9$ in more than $12 \mathrm{~min}$, compared with the case of the vessel equipped with 16 longitudinal finned tubes.

As extracted from the above results, it is clear that the case of using a vessel equipped with 16 longitudinal finned tubes is the most efficient way to enhance the hydrogenation kinetics when using both $\mathrm{LaNi}_{5}$ and the $\mathrm{AB}_{2}$-alloy. When using LaNi5 as the operating hydride the case of the vessel equipped with 60 embedded cooling tubes presents the same kinetic behaviour with the case of the vessel equipped with 12 longitudinal finned tubes, so in that way, by using extended surfaces to enhance the heat exchange can reduce the total number of tubes from 60 to 12 . For the case of using the AB2-type material as the operating hydride the performance of the extended surfaces is more dominant and more effective comparing to the case of using the embedded tubes, especially for the case of the longitudinal extended surfaces 
Fig 12.Comparison of all the studied heat management scenarios. Figure $12 a$ and $12 b$ present the comparison when using LaNi5 as the operating material. Figure 12c and 12d shows the the comparison when using the AB2-type intermetallic as the operating material.

\section{Conclusions}

In the current work, three different heat management scenarios were examined, for both the hydrogenation and dehydrogenation process. The three different scenarios include the case of the embedded cooling/heating tubes, the case of using transverse finned tubes and the case of the longitudinal finned tubes. A detailed optimization study was also presented in order to choose the optimized geometries for the finned tube geometries and the optimum geometry for the transverse finned tubes is the combination of 30 fins (distance between the fins 9.8 $\mathrm{mm}$ ) with radius $8 \mathrm{~mm}$ and thickness $2 \mathrm{~mm}$ and the optimum geometry for the longitudinal finned tubes is the combination of 12 fins with each fin height $5 \mathrm{~mm}$ and thickness $0.5 \mathrm{~mm}$. Furthermore, two different types of hydrides were studied as possible candidate materials for using as the first stage alloys in a two-stage metal hydride hydrogen compression system, in terms of the hydrogenation kinetics under the same conditions and the same heat management scenarios. It has to be noted that both the hydrogenation and dehydrogenation process described in detail when using $\mathrm{LaNi}_{5}$ as the operating material. The results showed that for the hydrogenation process, when using $\mathrm{LaNi}_{5}$ for the case in vessel equipped with the embedded tubes the cases of 48 and 60 tubes are able to achieve $X=0.9$ in less than $2000 \mathrm{~s}$, while the use of an additional external jacket can enhance the hydrogenation process by almost $4 \mathrm{~min}$, for the cases of 36, 48 and 60 tubes. For the dehydrogenation process the results showed that the usage of 36, 48 and 60 tubes can lead the reaction and the system is able to reach $\mathrm{X}=0.1$ in less than $2000 \mathrm{~s}$, while the use of the additional external jacket can accelerate the reaction by almost 7 min. For a vessel equipped with transverse finned tubes, for the hydrogenation process, the results showed that only the case of 16 finned tubes can reach $\mathrm{X}=0.9$ within $2000 \mathrm{~s}$, but when using an additional jacket both the cases of 12 and 16 finned tubes can achieve the target. Furthermore, the presence of the external jacket accelerates the process by 4-5 min. For the dehydrogenation process the results showed that only the case of 16 finned tubes can reach $X=0.1$ within $2000 \mathrm{~s}$, and the presence of the external jacket allows the system to achieve $X=0.1$ in less than $2000 \mathrm{~s}$ for both the cases of 12 and 16 finned tubes. For a vessel equipped with longitudinal finned tubes the hydrogenation reaction is fast and both the cases of the vessel equipped with 12 and 16 finned tubes can achieve $X=0.9$ in less than $2000 \mathrm{~s}$ and the presence of the additional external jacket does not affect the reaction in a great manner for the case of 16 finned tubes. For the dehydrogenation process the case of both 12 and 16 finned tubes allows the system to achieve $X=0.1$ in less than 2000 s. Finally, for the comparison of the two candidate materials for the first stage of the metal hydride hydrogen compression system, $\mathrm{LaNi}_{5}$ and the $\mathrm{AB}_{2}$-type (Ti-Zr-Mn based) intermetallic showed that the hydrogenation reaction kinetics in all the heat management scenarios showed an almost similar behaviour for the case of the embedded tubes and the transverse finned tubes is almost the same, but for the case of the longitudinal fins the $\mathrm{AB}_{2^{-}}$ type intermetallic presents faster response than $\mathrm{LaNi}_{5}$ ( $4.5 \mathrm{~min}$ for the 12 finned tubes and 5 min for the 16 finned tubes), making the $\mathrm{AB}_{2}$-type (Ti-Zr-Mn based) intermetallic a very potential candidate for the first stage material of the two-stage compression system. 


\begin{tabular}{|c|c|c|c|}
\hline \multicolumn{2}{|c|}{ Nomenclature } & \multicolumn{2}{|c|}{ Subscripts } \\
\hline $\mathrm{C}_{\mathrm{a}}$ & Absorption Reaction Constant, $s^{-1}$ & a & Absorption \\
\hline $\mathrm{C}_{\mathrm{d}}$ & Desorption Reaction Constant, $s^{-1}$ & & \\
\hline $\mathrm{C}_{\mathrm{p}}$ & Specific Heat, J/kg-K & & \\
\hline $\mathrm{E}_{\mathrm{a}}$ & Activation Energy for Absorption, $\mathrm{J} / \mathrm{molH}_{2}$ & d & Desorption \\
\hline $\mathrm{E}_{\mathrm{d}}$ & Activation Energy for Desorption, $\mathrm{J} / \mathrm{molH}_{2}$ & e & Effective \\
\hline h & Heat Transfer Coefficient, $\mathrm{W} / \mathrm{m}^{2} \mathrm{~K}$ & eq & Equilibrium \\
\hline $\mathrm{k}$ & Thermal Conductivity, $\mathrm{W} / \mathrm{m}-\mathrm{K}$ & $\mathrm{f}$ & External Heater/Cooler \\
\hline K & Permeability, $m^{2}$ & g & Gas \\
\hline M & Molecular Weight, $\mathrm{kg} / \mathrm{mol}$ & $\mathrm{i}$ & Initial \\
\hline $\mathrm{m}$ & Kinetic Expression & s & Solid \\
\hline $\mathrm{n}$ & Number of Hydrogen Moles & ss & Saturation \\
\hline $\mathrm{P}$ & Pressure, bar & $G r$ & ters \\
\hline $\mathrm{R}$ & Gas Global Constant, J/mol-K & $\varepsilon$ & Porosity \\
\hline $\mathrm{t}$ & Time (s) & $\mu$ & Dynamic Viscosity, $\mathrm{kg} / \mathrm{ms}$ \\
\hline $\mathrm{T}$ & Temperature $(K)$ & $\rho$ & Density, $\mathrm{kg} / \mathrm{m}^{3}$ \\
\hline $\mathrm{v}$ & Gas Velocity, m/s & $\Delta \mathrm{H}$ & Reaction Enthalpy, J/mol \\
\hline $\mathrm{V}$ & Volume, $m^{3}$ & $\Delta S$ & Reaction Entropy, J/mol-K \\
\hline
\end{tabular}




\section{Acknowledgement}

The current work was supported financially by the E.S.C.H.E.R (Engineering Safe and Compact Energy Reserves) Project, EPRSC Reference EP/KO21117/1. 


\section{References}

[1] S.S Makridis, E.I Gkanas, G. Panagakos, E.S Kikkinides, A.K Stubos, P. Wagener, S. Barcikowski, Int. J. Hyd. Energy 38 (2013) 11530-11535.

[2] G. Walker, Solid state hydrogen storage: Materials and chemistry, Woodhead Publishing, Cambridge, UK, 2008.

[3] L. Schlapbach, A Zuttel, Nature 414 (2001) 353-358.

[4] J. Ni, H. Liu, Int. J. Hyd. Energy 32 (2007) 2567-2572.

[5] E.I Gkanas, S.S Makridis, A.K Stubos, Computer Aided Chemical Engineering 32 (2013) 379-384.

[6] P. Muthukumar, K.S Patel, P. Sachan, N. Singhal, International Journal of Energy Research 37 (2012) 37973806.

[7] E.D Koultoukis, E.I Gkanas, S.S Makridis, C.N Christodoulou, D. Fruchart, A.K Stubos, International Journal of Energy Research 38 (2014) 477-486.

[8] F.S. Yang, Z.X. Zhang, G.X. Wang, Z.W. Bao, J.C. Diniz da Costa, V. Rudolph, Applied Thermal Engineering 31 (2011) 2749-2756.

[9] S. Ahmed, S Srinivasa Murthy, Renewable Energy 29 (2004) 615-631.

[10] S. Anvarasu, P. Muthukumar, S.C. Mishra, In. J. Hyd. Energy 39 (2014) 15549-15562.

[11] A. Mazzucco, M. Dornheim, M. Sloth, T. R. Jensen, J. O. Jensen, M. Rokni, Int. J. Hyd. Energy 39 (2014) 17054-17074.

[12] B.D MacDonald, A.M Rowe, Int. J. Hyd. Energy 31 (2006) 1721-1731.

[13] K. B. Minko, V. I. Artemov , G. G. Yankov, Applied Thermal Engineering 76 (2015) 175-184.

[14] Meng-Lung Tsai, Tian-Shiang Yang, Int. J. Hyd. Energy 35 (2010) 11052-11063.

[15] F. Laurencelle, J. Goyette, Int. J. Hyd. Energy 32 (2007) 2957-2964.

[16] Nagel M, Komazaki Y, Suda S. Journal of Less-Common Meteorology 1987;131:426.

[17] Bershadsky E, Josephy Y, Ron M, J. Less Common Met. 153 (1989) 65-78.

[18] Kim K, Feldman K, Lloyd G, Int J Hydrogen Energy, 23 (1998) 355-362.

[19] Kim KJ, Lloyd GM, Feldman Jr KT, Razani A, Appl Therm Eng 18 (1998) 1325-1336.

[20] Sanchez AR, Klein H-P, Groll M, Int J Hydrogen Energy 28 (2003) 515-527.

[21] M. Visaria, I. Mudawar, T. Pourpoint, S. Kumar, Int. J. Heat Mass Transfer, 53 (2010) 2229-2239.

[22] Z. Bao, Z. Wu, S. N. Nyamsi, F. Yang, Z. Zhang, Appl Therm Eng 52 (2013) 97-108. 
[23] C. A. Krokos, D. Nikolic, E. S. Kikkinides, M. C. Georgiadis, A. K. Stubos, Int J Hydrogen Energy 34 (2009) 9128-9140.

[24] M. Visaria, I. Mudawar, T. Pourpoint, Int. J. Heat Mass Transfer, 54 (2011) 413-423.

[25] T. Oi, K. Maki, Y. Sakaki, J. Power Sources 125 (2004) 52-61.

[26] H. Dhaou, A. Souahlia, S. Mellouli, F. Askri, A. Jemni, S. Ben Nasrallah, Int J Hydrogen Energy 35 (2010) 1674-1680.

[27] F. Askri, M. Ben Salah, A. Jemni, S. Ben Nasrallah, Int J Hydrogen Energy 34 (2009) 897-905.

[28] M. Raju, S. Kumar, Int J Hydrogen Energy 37 (2012) 2767-2778.

[29] M. Visaria, I. Mudawar, Int J Hydrogen Energy 37 (2012) 5735-5749.

[30] Y. Liu, H. Wang, A. K. Prasad, S. G. Advani, Int J Hydrogen Energy 39 (2014) 10552-10563.

[31] E.I. Gkanas, D.M. Grant, A.D. Stuart, C.N. Eastwick, D. Book, S. Nayebossadri, L. Pickering, G.S. Walker, Journal of Alloys and Compounds 645 (2015) S18-S22.

[32] P. Muthukumar, K.S Patel, P. Sachan, N. Singhal, Int. J. Hyd. Energy, 37 (2012) 3797-3806.

[33] T. Nashizaki, K. Miyamoto, J. Less Common Metals, 89 (1983) 559-566. 